Research Article

\title{
Separating and Characterizing Functional Nitrogen Degraders via Magnetic Nanoparticle-Mediated Isolation
}

\author{
Yujiao Sun (D), Meng Yin, Danyang Zheng, Lei Wang, Xiaohui Zhao, and Jie Li \\ College of Water Science, Beijing Normal University, Beijing 100875, China \\ Correspondence should be addressed to Yujiao Sun; sun201405@163.com
}

Received 25 December 2019; Revised 7 March 2020; Accepted 9 March 2020; Published 14 April 2020

Guest Editor: Ibrahim H. Alsohaimi

Copyright (C) 2020 Yujiao Sun et al. This is an open access article distributed under the Creative Commons Attribution License, which permits unrestricted use, distribution, and reproduction in any medium, provided the original work is properly cited.

\begin{abstract}
Magnetic nanoparticle-mediated isolation (MMI) is a new method for isolating active functional microbes from complex microorganisms without substrate labeling. In this study, the composition and properties of magnetic nanoparticles (MNPs) were characterized by a number of techniques, indicating that MNPs have characteristics such as microinterfaces and can be efficiently fixed on the surface of microbial cells. It also introduced the MMI technology in activated sludge after stable long-term treatment. With further addition of promotor carbon sources, the enrichment of the functional nitrogen degraders in MMI was significantly higher than in samples without MNPs, showing the advantages of MMI in identifying the active degraders. Redundancy analysis (RDA) also showed that the functional nitrogen degraders such as Comamonadaceae_unclassified and Thiobacillus absolutely dominated in situ ammonia degradation, and the change in dominant genera had the same trend as the degradation rate of ammonia nitrogen. In the magnetically functionalized system, the separated functional nitrogen degraders significantly improved ammonia nitrogen degradation efficiency, making it basically stable at more than $80 \%$, up to $91.6 \%$. These results prove that the complex flora created after the addition of MNPs is more adaptable to newly introduced pollutants, and MMI is a powerful tool for studying pollutant-degrading microorganisms under in situ conditions.
\end{abstract}

\section{Introduction}

With China's rapid industrial development, petrochemical, gas, pharmaceutical, and metallurgical industries have produced and will continue to produce vast amounts of wastewater that contain high concentrations of ammonia nitrogen. In 2015, the discharge of ammonia nitrogen pollutants was as high as 2.299 million tons [1]. The direct discharge of excessive ammonia nitrogen into water bodies causes eutrophication. Moreover, nitrate and nitrite, the oxidation products of ammonia, will affect aquatic ecosystems and human health [2]. Since 1998, China has revised a series of environmental quality standards to control the discharge of ammonia nitrogen and nitrate into water bodies. However, given the outdated industrial equipment and ineffective pollution control in China, large amounts of wastewater with excessive levels of ammonia continue to be discharged into water systems. Therefore, research on the removal of ammonia from water is crucial.
Biological denitrification is the most widely used nitrogen removal method because of its simple operation and excellent ammonia nitrogen removal rate. Moreover, biological denitrification does not produce secondary pollution. Some new methods with high efficiencies and low consumption have been applied to wastewater treatment in recent years [3]. These methods include simultaneous nitrification and denitrification, short-range nitrification and denitrification, and anaerobic oxidation.

Microorganisms that are involved in biological denitrification include ammonia-oxidizing Archaea (AOA), ammonia-oxidizing bacteria (AOB), and nitrite-oxidizing bacteria (NOB) [4]. AOB are Gram-negative autotrophs are widely found in soil, water, and sewage treatment systems [5]. There are two categories of AOB: $\beta$-proteobacteria, which includes Nitrosomonas and Nitrosospira, and $\gamma$-proteobacteria, which includes Nitrosococcus [6, 7]. Archaea has three main phyla: Euryarchaeota, Crenarchaeota, and Thaumarchaeota. AOA is another microorganism that can 
oxidize ammonia nitrogen and is more dominant than $\mathrm{AOB}$ in nutrient-poor environments [8,9]. AOA contains two main clusters: Thaumarchaeota groups I.1a and I.1b [10]. Pure strains of Nitrosopumilus maritimus SCM1 [11] and Nitrosocaldus yellowstonii [12] have been isolated. Pure cultures of Candidatus Nitrosopumilus sediminis AR2 [13], Candidatus Nitrosoarchaeum limnia SFB1 [14], Candidatus Nitrosotalea devanaterra [15], and Candidatus Nitrosoarchaeum limnia BG20 [16] have been obtained from hot springs, soils, and sediments and through enrichment. NOB are Gram-negative bacteria that complete the oxidation of nitrite to nitrate. The NOB Nitrobacter and Nitrospira are currently used in wastewater biological treatment [17-21].

The majority of microbes (>99\%) with crucial environmental functions cannot be cultivated under standard laboratory conditions [22]. Ammonia nitrogen-degrading bacteria are particularly difficult to culture. Moreover, given the complexity of the microbial community structure, microorganisms cannot be effectively separated and cultured individually. Thus, studying the in situ ecological function of microorganisms using traditional culture methods is difficult. Magnetic nanoparticle-mediated isolation (MMI) is a cultivation-independent method which has been recently developed for the in situ separation of active functional microorganisms from complex microbial systems. As a universal tool for remote operation and control, the magnetic nanoparticles (MNPs) can be used to functionalize living cells, and the MNP functionalization of living cells can selectively control cells in vivo [23-25]. Therefore, this technology can provide a powerful tool to identify functional living cells. After all the microorganisms in the system are functionalized, a specific contaminant substance is added as the sole carbon source. Degrading bacteria will then use this material to multiply quickly, and during the process of microbial proliferation, the density of MNPs on its surface gradually decreases, thus eventually losing its magnetic properties and cannot be captured by an external magnetic field. After magnetic separation, functional bacteria are obtained to achieve in situ enrichment and separation of target microorganisms [26]. Microbial cells that have been isolated by this technique remain active and can be used in the study of microbial community structure and ecological functions.

Some scholars have used MNPs for the separation and screening of pollutant-degrading bacteria. For example, Wang et al. [27] used $\mathrm{Fe}_{3} \mathrm{O}_{4} \mathrm{MNP}$ separation technology to study alkane-degrading bacteria in soil and experimentally confirmed that Oxalobacteraceae and Moraxellaceae are functional microorganisms in the degradation process. In this study, the composition and properties of the MNPs were characterized by some methods, and MMI was used for the first time in long-term domesticated activated sludge systems, adding urea as a carbon source to enhance the activity of ammonia nitrogen-degrading bacteria. MMI was used to realize the in situ separation of functional ammonia nitrogen-degrading bacteria, and its effect on ammonia nitrogen degradation in an activated sludge system after longterm domestication was studied. By high-throughput DNA sequencing, the microbial community structure was analyzed to reveal the dominant microorganisms in the ammonia nitrogen degradation process. Our findings aim to provide a novel approach for improving the quality of activated sludge after long-term domestication.

\section{Materials and Methods}

2.1. Contaminated Sites and Sample Collection. Activated sludge was collected from a wastewater treatment plant (WWTP) in Shanxi Province, China $\left(38^{\circ} 42^{\prime} \mathrm{N}, 110^{\circ} 10^{\prime} \mathrm{E}\right)$. This plant uses sequencing batch reactor activated sludge process to treat domestic wastewater. The activated sludge was taken from a sequencing batch reactor in the field. The operating conditions of the reactor were stable at the time of sampling, and the removal rates of chemical oxygen demand (COD) and $\mathrm{NH}_{3}-\mathrm{N}$ were above $95 \%$. The samples were filtered, centrifuged, and stored at $4^{\circ} \mathrm{C}$ for further study.

2.2. Synthesis and Characterization of MNPs. MNPs were synthesized according to a previously reported method [28]: $1 \mathrm{~mL}$ of $\mathrm{FeCl}_{2}(1.0 \mathrm{M})$ was mixed with $2 \mathrm{~mL}$ of $\mathrm{FeCl}_{3}(2.0 \mathrm{M})$. Then, $25 \mathrm{~mL}$ of $\mathrm{NaOH}(2.0 \mathrm{M})$ was added dropwise to the mixture. After 30 min of continuous shock, the black $\mathrm{Fe}_{3} \mathrm{O}_{4}$ composite MNPs were retrieved using a magnet and then washed with $30 \mathrm{~mL}$ of deionized water several times until the $\mathrm{pH}$ was neutral (7.0). The concentration of synthetic MNPs was $9.1 \mathrm{~g} / \mathrm{L}$.

The morphology of MNPs was investigated by scanning electron microscopy (SEM, S4800, Hitachi, Tokyo, Japan) and transmission electron microscopy (TEM, JEM-2100F, Jeol, Tokyo, Japan). The elemental composition and distribution were determined using TEM coupled with energydispersive X-ray spectroscopy (TEM-EDS, X-MAXN, HORIBA, Fukuoka, Japan). Nitrogen adsorption-desorption isotherms were obtained using a QUADRASORB SI Autosorb-SI analyzer (Quantachrome, Boynton, FL, USA); the analysis conditions were set to a degassing temperature of $100^{\circ} \mathrm{C}$ and a degassing time of 6 hours, and specific surface area and pore size distribution were evaluated by the Brunauer-Emmett-Teller (BET) method and the Barrett-Joyner-Halenda (BJH) method. X-ray diffraction (XRD) patterns of MNPs were recorded on a PANalytical B.V instrument (X'pert pro MPD, Almelo, Holland) using a Co source. XRD analysis was carried out to study the crystallinity of the MNPs on a diffractometer (X'pert pro MPD, Almelo, Holland) with nickel-filtered $\mathrm{Cu} \mathrm{K} \alpha$ X-ray photoelectron spectroscopy (XPS, ESCALAB 250XI, Thermo, MA, USA). The measurements were used to determine the compositions and chemical states of the MNPs. The magnetic properties were measured with a vibrating sample magnetometer (VSM-Versalab, Quantum Design, San Diego, USA).

2.3. Functionalization of Sludge Samples. The activated sludge was functionalized with MNPs according to a previously reported method [27]. Sludge and nanoparticle concentrations were determined as follows: $1.0 \mathrm{~mL}$ of synthetic MNPs was mixed with 0.01 to $1.099 \mathrm{mg}$ of sludge 
samples. After 5 min of slight shaking, and a magnet was used to attract the magnetized functional sludge. Microbial concentrations (copies/mL) in the supernatant and magnetic-functionalized sludge were determined by real-time fluorescence quantitative PCR (qPCR).

2.4. Biodegradation of Ammonia Nitrogen. There were four experimental groups: raw sludge with/without urea (CKU/ CKN) and MNP-functionalized sludge with/without urea (MNPU/MNPN). Urea was added as the sole carbon source to the control reaction systems, and $20 \mathrm{~mL}$ of $20 \mathrm{~g} / \mathrm{L}$ urea solution was added to the reaction system every 3 days. Ammonia nitrogen was maintained in a supersaturated state during the experiment. The experiment was conducted at $25^{\circ} \mathrm{C}$ for 40 days. Samples were collected on days $0,5,10,20$, 30 , and 40 of the experiment. All the samples from CKU and CKN were directly stored for chemical and biological analysis. For water samples from MMI microcosms, the functional ammonia nitrogen-degrading bacteria were separated from the inert microbes by a magnet and remained in the aqueous phase (magnetic-free cells, MFCs), followed by chemical and biological analysis. MFCs from MNPN and MNPU samples were designated as MFCN and MFCU, respectively.

2.5. DNA Extraction, Amplification, and Sequencing. Sludge DNA was extracted using the phenol-chloroform extraction method. DNA samples were purified using a DNA product purification kit (TIANquick Midi Purification Kit, Tiangen, China). To determine fragment lengths, purified DNA was resolved via electrophoresis on $1 \%$ agarose gel. The concentration and purity (concentration $>50 \mathrm{ng} / \mu \mathrm{L}$, OD 260/280 between 1.8 and 1.2) of DNA samples were quantified with an ND-2000 UV-Vis spectrophotometer (NanoDrop Technologies, USA).

Due to the moderate molecular size of $16 \mathrm{~S}$ rRNA, its genetic sequence changes slowly during the evolution of organisms, which can be used to mark the evolutionary distance and kinship of organisms, becoming the most commonly used biomarker in current research [29]. To determine the microbial community structure, the fragments of hypervariable V3V4 variable region of 16S rRNA genes were amplified with a primer pair of $338 \mathrm{~F}\left(5^{\prime}-\right.$ ACTCCTACGGGAGGCAGCAG- $\left.3^{\prime}\right)$ and 806R (5'GGACTACHVGGGTWTCTAAT- ${ }^{\prime}$ ). PCR reactions, containing $25 \mu \mathrm{l} 2 \mathrm{x}$ Premix Taq (Takara Biotechnology, Dalian Co. Ltd., China) and $1 \mu \mathrm{l}$ of each primer $(10 \mathrm{mM})$ and $3 \mu \mathrm{l}$ DNA $(20 \mathrm{ng} / \mu \mathrm{l})$ template in a volume of $50 \mu \mathrm{l}$ were amplified by thermocycling: $5 \mathrm{~min}$ at $94^{\circ} \mathrm{C} ; 30$ cycles of $30 \mathrm{~s}$ at $94^{\circ} \mathrm{C} ; 30 \mathrm{~s}$ at $52^{\circ} \mathrm{C}$; and $30 \mathrm{~s}$ at $72^{\circ} \mathrm{C}$; followed by $10 \mathrm{~min}$ at $72^{\circ} \mathrm{C}$. The length and concentration of the PCR products were detected via $1 \%$ agarose gel electrophoresis, purified by EZNA Gel Extraction Kit (Omega, USA). Sequencing libraries were generated using NEBNext ${ }^{\circledR}$ Ultra $^{\mathrm{TM}}$ DNA Library Prep Kit for Illumina ${ }^{\circledR}$ (New England Biolabs, MA, USA) following manufacturer's recommendations, and index codes were added. Finally, the library was sequenced on an IlluminaHiseq2500 platform and $250 \mathrm{bp}$ paired-end reads were generated. Sequence analysis was performed by Usearch software. Sequences with $\geq 97 \%$ similarity were assigned to the same OTU. An OTU is thought to possibly represent a species.

2.6. Chemistry and Data Analysis. International standard methods [30] were used to measure $\mathrm{NH}_{4}^{+}-\mathrm{N}, \mathrm{NO}_{2}^{-}-\mathrm{N}$, and $\mathrm{NO}_{3}^{-}-\mathrm{N}$. The data analysis was performed on Excel 2016. RDA was processed and plotted using CANOCO 4.5 to analyze the relationship between ammonia nitrogen degradation efficiency and the functional ammonia nitrogendegrading bacteria.

\section{Results and Discussion}

3.1. MNP Characterization. The TEM images show the morphology and nanoparticle distribution of MNPs (Figure 1(a)). The synthesized MNPs were roughly globular and aggregated together because of magnetization (Figure 1(a)). The diameters of the MNP aggregates were in the range of $50-100 \mathrm{~nm}$. As shown in Figure 1(b), the MNPs have a diameter of approximately $5-10 \mathrm{~nm}$, which are much smaller than the diameter of the cell. Due to the small size effect and high surface energy, MNPs could be efficiently fixed on the surface of microbial cells. The MNPs had evident lattice fringes, and the crystalline composition was further elucidated by HRTEM. The interplanar distances of MNPs were $0.253 \mathrm{~nm}$ and $0.148 \mathrm{~nm}$, corresponding to the (311) and (440) lattice planes of $\mathrm{Fe}_{3} \mathrm{O}_{4}$, respectively. EDS mapping showed the distribution of elements (Figure 1(c)). Figure 1(d) clearly shows that $\mathrm{C}$ was mainly distributed in the space between particles, while $\mathrm{O}$ and $\mathrm{Fe}$ were uniformly distributed in the particles.

The representative XRD pattern of the obtained material is shown in Figure 2(a). The pattern had diffraction peaks at $2 \theta$ of $30.2^{\circ}, 35.5^{\circ}, 43.3^{\circ}, 53.6^{\circ}, 57.1^{\circ}, 62.7^{\circ}$, and $74.2^{\circ}$ which could be assigned to the (311), (222), (400), (422), (511), (440), and (533) planes of $\mathrm{Fe}_{3} \mathrm{O}_{4}$ (JCPDS 88-0315). The elemental composition and chemical states of the $\mathrm{Fe}_{3} \mathrm{O}_{4} @ \mathrm{C} /$ $\mathrm{CNF}$ sere further investigated by XPS analysis. According to the survey scan (Figure 2(b)), there were mainly three elements, which were $\mathrm{C}, \mathrm{O}$, and $\mathrm{Fe}$. The $\mathrm{O}$ 1s spectrum (Figure 2(c)) had two peaks at $530.3 \mathrm{eV}$ and $531.8 \mathrm{eV}$, corresponding to lattice oxygen $(\mathrm{M}-\mathrm{O})$ of $\mathrm{Fe}_{3} \mathrm{O}_{4}$ and hydroxyl groups $(-\mathrm{O}-\mathrm{H})$, respectively. The $\mathrm{C}$ 1s spectrum (Figure 2(d)) consisted of three peaks at $285.0 \mathrm{eV}, 286.3 \mathrm{eV}$, and $288.9 \mathrm{eV}$, which correspond to carbon bonds (C-C), carbon oxygen bonds (C-O), and carbon hydrogen bonds $\left(\mathrm{C}-\mathrm{CO}_{3}\right)$, respectively. Two peaks with binding energies at $711.5 \mathrm{eV}$ and $724.9 \mathrm{eV}$ were obtained in the $\mathrm{Fe} 2 \mathrm{p}$ spectrum (Figure 2(e)) and could verify the presence of $\mathrm{Fe}_{3} \mathrm{O}_{4} \cdot \mathrm{Fe}_{3} \mathrm{O}_{4}$ is a typical magnetic material, and the magnetic hysteresis loop of the obtained material at maximum field strength of $30 \mathrm{kOe}$ is shown in Figure 2(f). The saturation magnetization (Ms) of the material was $22.01 \mathrm{emu} / \mathrm{g}$, the coercivity (Hc) was 105.22 Oe, and the remnant magnetization (Mr) was $1.03 \mathrm{emu} / \mathrm{g}$. 


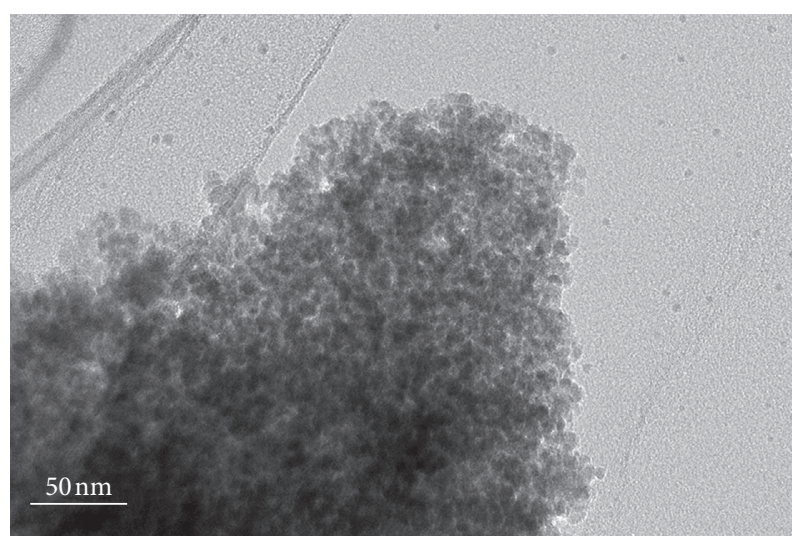

(a)

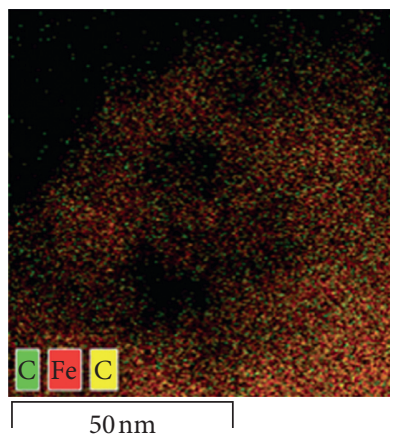

(c)

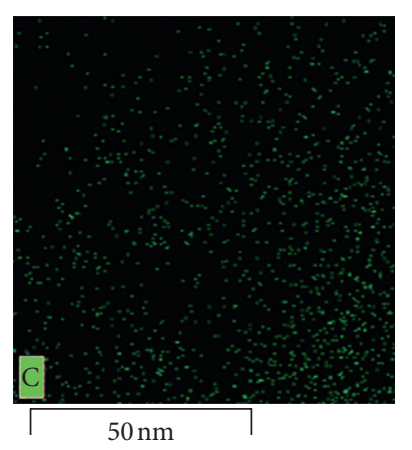

(d)

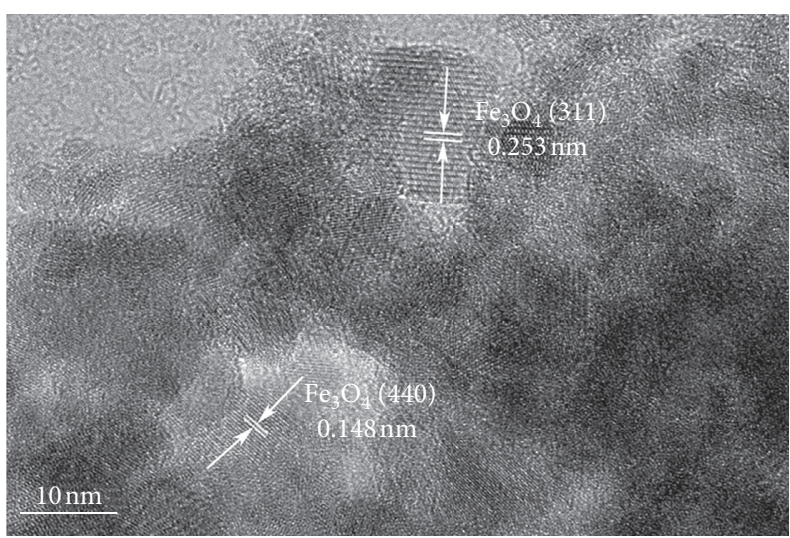

(b)

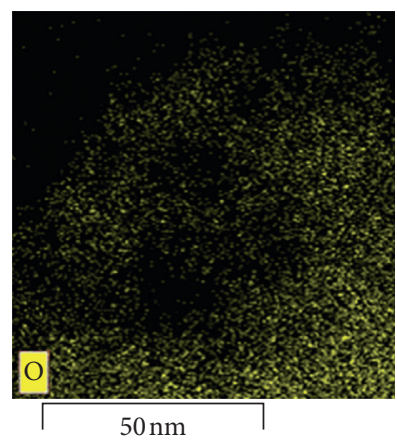

(e)

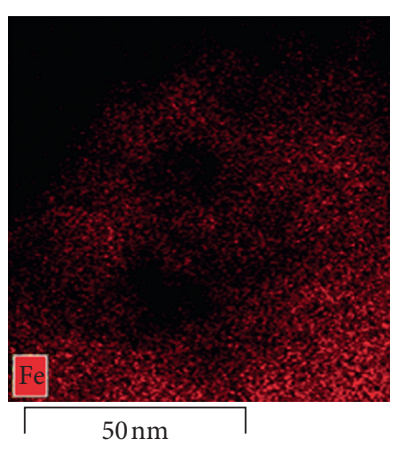

(f)

Figure 1: The TEM image (a), HRTEM image (b), EDS mapping layered image (c), element C layered image (d), element O layered image (e), and element Fe layered image (f) of the MNPs.

The $\mathrm{N}_{2}$ adsorption-desorption isotherms of MNPs are shown in Figure 3. MNPs show type II adsorption isotherms, so the surface area was calculated as $213.180 \mathrm{~m}^{2} / \mathrm{g}$ by the BET method (inset). According to the BJH method, MNPs had typical micropores with pore widths of $0.57,1.18$, and $2.5-4.3 \mathrm{~nm}$. The pore volume was $0.092 \mathrm{~cm}^{3} / \mathrm{g}$. In recent years, some researchers have developed a series of nanomaterials with nano- $\mathrm{Fe}_{3} \mathrm{O}_{4}$ as the core. For example, Kazemifard et al. [31] synthesized a series of magnetic $\mathrm{KOH} /$ $\mathrm{Fe}_{3} \mathrm{O}_{4}$ at $\mathrm{Al}_{2} \mathrm{O}_{3}$ core-shell nanomaterials via the incipient wetness impregnation method, with a maximum surface area of $20.46 \mathrm{~m}^{2} / \mathrm{g}$. Bangari et al. [32] developed $\mathrm{Fe}_{3} \mathrm{O}_{4}$ functionalized boron nitride nanosheets with a surface area of $119 \mathrm{~m}^{2} / \mathrm{g}$. It can be seen that the surface area of these materials is much smaller than the MNPs prepared by the coprecipitation method in this paper, while the comparatively large surface area and pore volume provide more exposure opportunities and adsorption spaces. This also provides a large contact area between the magnetic nanoparticles and the cells.

\subsection{Optimal Conditions for the MNP Functionalization of} Sludge Microcosm. Microbes in activated sludge are attracted to synthetic MNPs via strong electrostatic interactions [33]. Magnetic hysteresis loop data (Figure 2(f)) show that MNPs have an extremely strong magnetic force, and magnetic separation can be achieved with conventional permanent magnets. Sludge magnetic functionalization results also showed that cells functionalized with MNPs were highly magnetic and could be readily collected. To achieve the highest magnetic functionalization efficiency using the lowest amount of MNPs, the optimal weight ratio of sludge to MNPs (from 0.01 to $1,099, \mathrm{w} / \mathrm{w}$ ) was quantitatively analyzed using qPCR. The functional efficiency of the sludge was expressed as the ratio of the number of microorganisms in the sludge to the total (supernatant and sludge) microbiological quantity. In this study, $100 \%$ magnetic functionalization efficiency of the sludge indicated that all the microorganisms in the sludge were magnetically functionalized, whereas $0 \%$ indicated that no sludge bacteria were magnetically functionalized. The magnetic functionalization efficiency of the sludge is shown in Figure 4. The results showed that when the ratio of sludge to MNPs was less than $549(\mathrm{w} / \mathrm{w})$, magnetic functionalization efficiency exceeded $90 \%$. When the ratio of sludge to MNPs exceeded $604(\mathrm{w} / \mathrm{w})$, the magnetic functionalization efficiency decreased rapidly. When the ratio increased to $1099(\mathrm{w} / \mathrm{w})$, magnetic functionalization efficiency was only $27.9 \%$. The low magnetic functionalization efficiency likely resulted from the large sizes of the sludge particles or microbial cells. Also, microbial cells are functionalized by MNPs via the interaction of MNPs with functional groups, such as carboxyl groups $(-\mathrm{COOH})$, thiol $(-\mathrm{SH})$, and amino groups $\left(-\mathrm{NH}_{2}\right)$, on microbial cell membranes [27, 34]. Given that all microbial cells have functional groups, magnetic functionalization is 


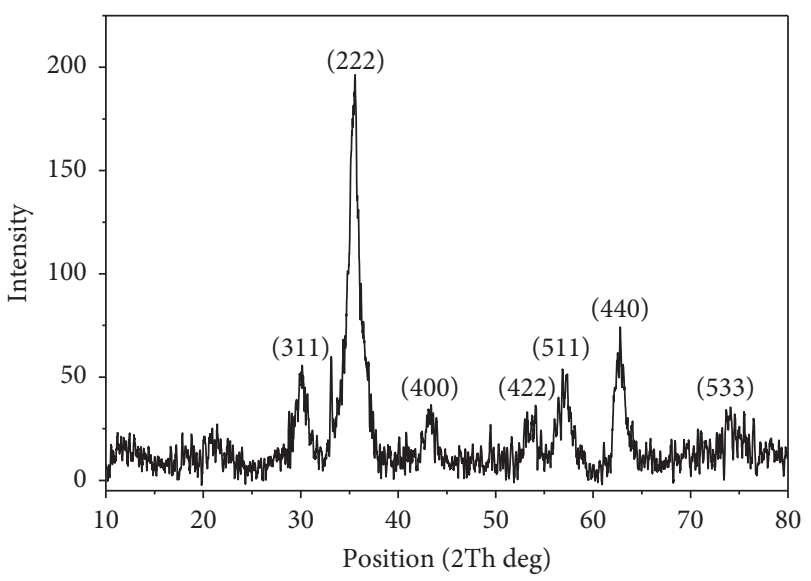

(a)

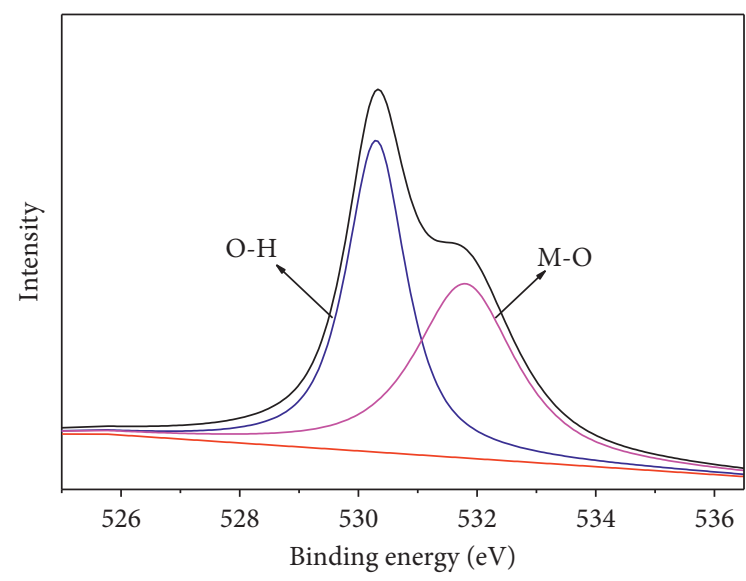

(c)

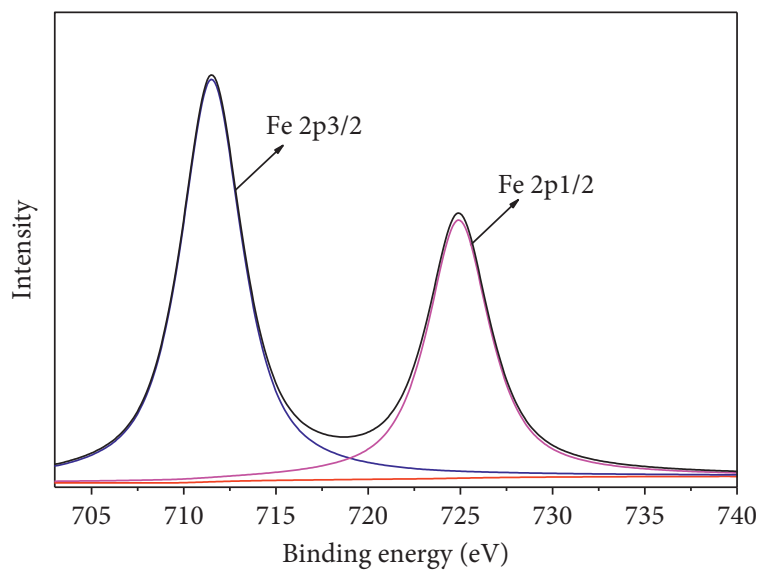

(e)

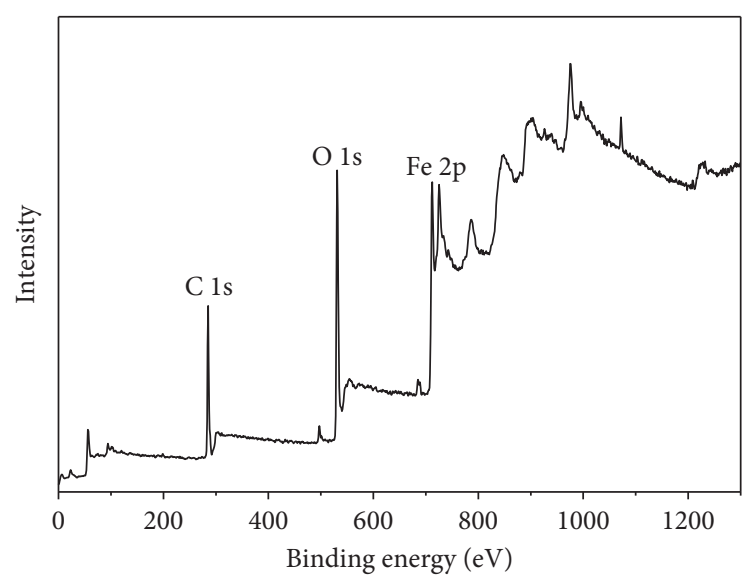

(b)

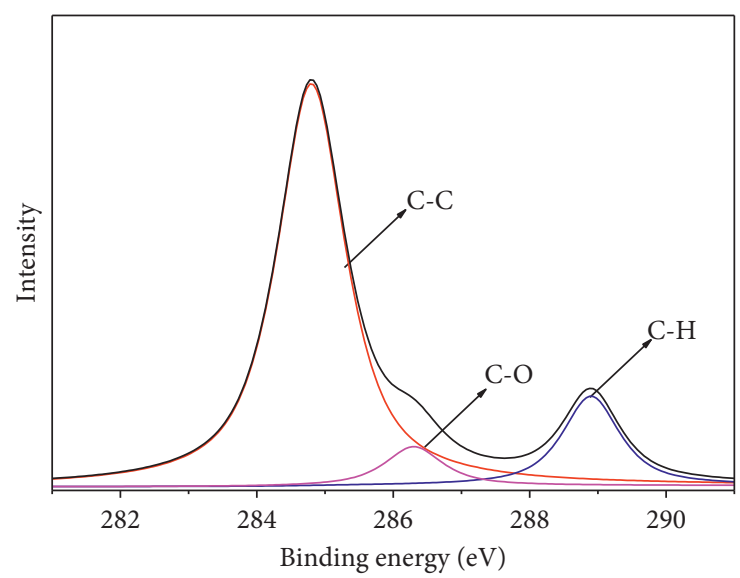

(d)

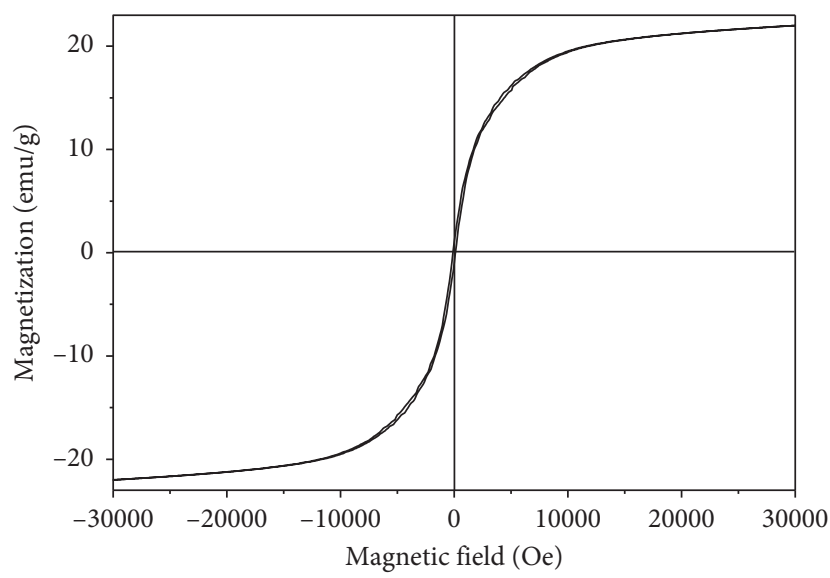

(f)

Figure 2: XRD patterns (a); survey scan (b); O 1s (c), C 1s (d), and Fe 2p (e) XPS spectra; and magnetic hysteresis loop (f) of MNPs.

not selective, and all microbial cells can be magnetized. Based on the results of the optimization experiment, $5 \mathrm{~g}$ of sludge was mixed with $9.1 \mathrm{mg}$ of MNPs for ammonia nitrogen biodegradation experiments.

3.3. Ammonia Nitrogen Degradation Experiment. The degradation of ammonia and the change in the concentrations of nitrite and nitrous nitrogen are shown in Figures 5 and 6.
The concentration of ammonia nitrogen showed a significant decrease with time in all groups added with urea (CKU and MNPU), while nitrate nitrogen and nitrite nitrogen accumulate continuously, indicating that there are a large number of active ammonia-oxidizing bacteria in the system [21]. Ammonia-oxidizing bacteria convert ammonia nitrogen into nitrite via ammoxidation, and nitrifying bacteria convert nitrite to nitrate via nitrification. It can also be seen from Figure 5 that the ammonia nitrogen degradation 


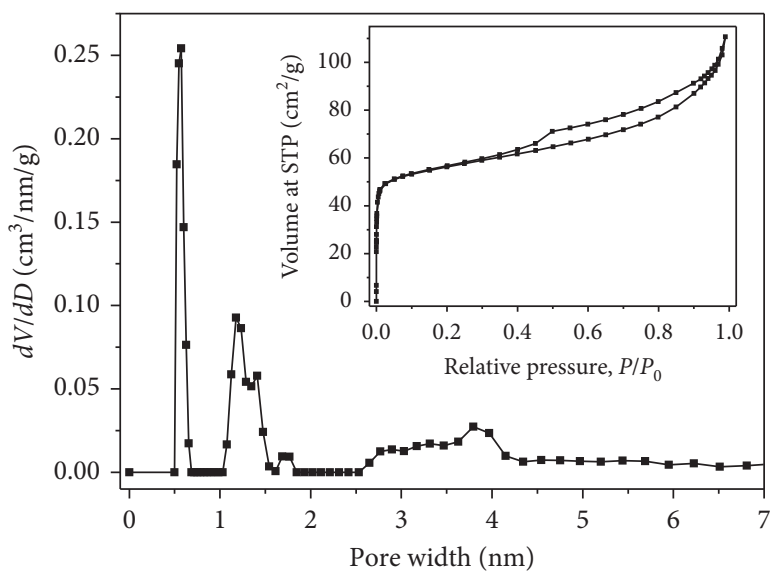

FIGURE 3: The pore size distribution and $\mathrm{N}_{2}$ adsorption-desorption isotherms of the MNPs.

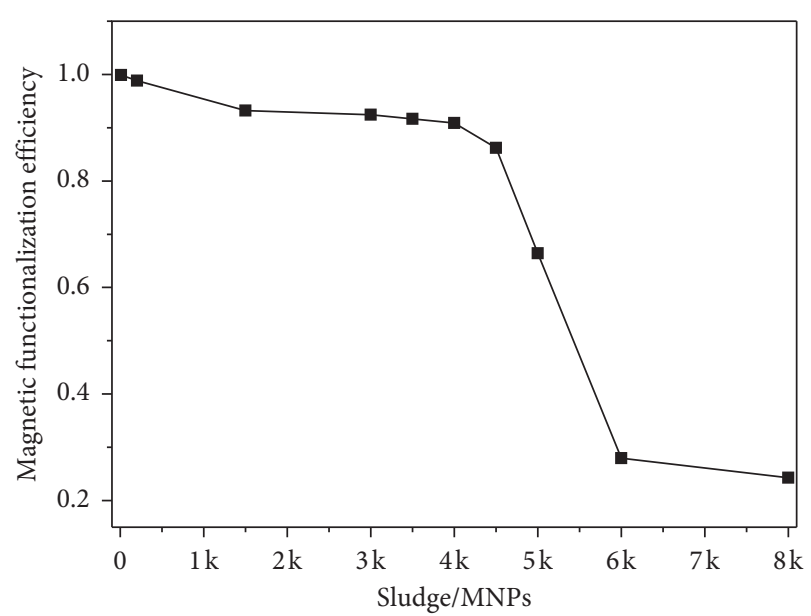

FIGURE 4: Sludge magnetic functionalization efficiency against the ratio of sludge to MNPs $(0.1 \sim 10,000, \mathrm{w} / \mathrm{w})$.

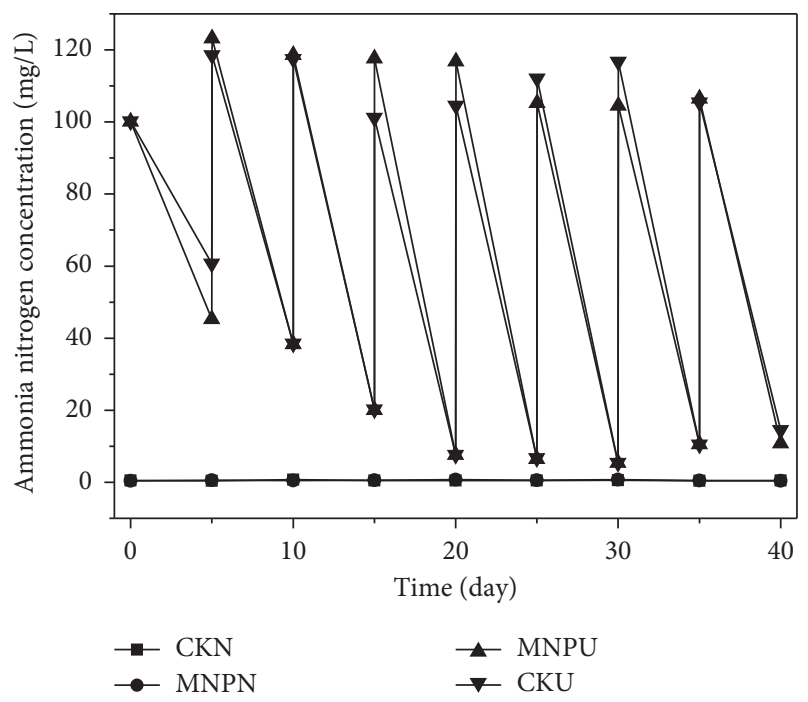

FIGURE 5: The degradation process of ammonia nitrogen, where arrows indicate the addition of ammonia to the reaction system. efficiency of the two groups with or without MNPs increased gradually as the reaction progressed. After 20 days, the degradation efficiency exceeded $90 \%$, indicating that MNPs had no effect on the bacterial activities or the ammonia nitrogen degradation performance [26]. And this is similar to the results of separation of functional alkane degradation agents using magnetic nanoparticles by Wang et al. [27]. The long-term acclimated sludge already contains a large number of target pollutant-degrading microorganisms. From Figure 6, it can be seen that after introducing a new pollutant, urea, in the long-term domesticated sludge, the concentrations of nitrate nitrogen and nitrite nitrogen were slightly higher than the samples without MNPs, indicating that functional microorganisms in the process of pollutant degradation can be enriched more thoroughly by adding MNPs in this system, and then the conversion of ammonia nitrogen into nitrous nitrogen and nitrate nitrogen may be promoted more completely. Therefore, the addition of MNPs can improve the quality of long-term acclimated sludge and make it more suitable for newly introduced pollutants.

\subsection{Microbial Community and Diversity Analysis}

3.4.1. Microbial Diversity in the Samples. High-throughput sequencing analysis was performed with DNA from CKN, CKU, MNPN, and MNPU samples. The microbial diversity index (Shannon) is obtained, and the results are shown in Figure 7. Shannon is the index commonly used to estimate microbial diversity and reflect alpha diversity in a sample. The larger the Shannon value, the higher the community diversity.

The Shannon indexes of microbial diversity in CKN and CKU were not significantly different. The former ranged from 8.38 to 8.75 , and the latter ranged from 8.42 to 8.65 . On day 0 , the Shannon indexes of MFCN and MFCU were similar at 3.32 and 3.64, respectively. The Shannon index of MNPN did not significantly change (3.19-3.32) during the experiment; this finding indicates that the number of microbial communities remained stable in this system. The Shannon index of MNPU gradually increased (3.64-5.12) as the experiment progressed, indicating that more microorganisms with ammonia nitrogen degradation function appeared in this process. Compared with the system without MNPs, it shows that only a part of the microorganisms can degrade ammonia nitrogen in this microbial community. On the contrary, it also shows that MMI can effectively isolate active functional microorganisms to improve the sludge quality after long-term domestication and make it more adaptable to external environmental changes.

3.4.2. Community Composition Analysis at the Phylum Level. Microbial classification based on phylum is shown in Figure 8. There was no significant difference between CKN and MNPN treatments, indicating no microbial community change in the groups with or without MNP functionalization. Thus, MNP functionalization did not change the microbial activities or community structure. 


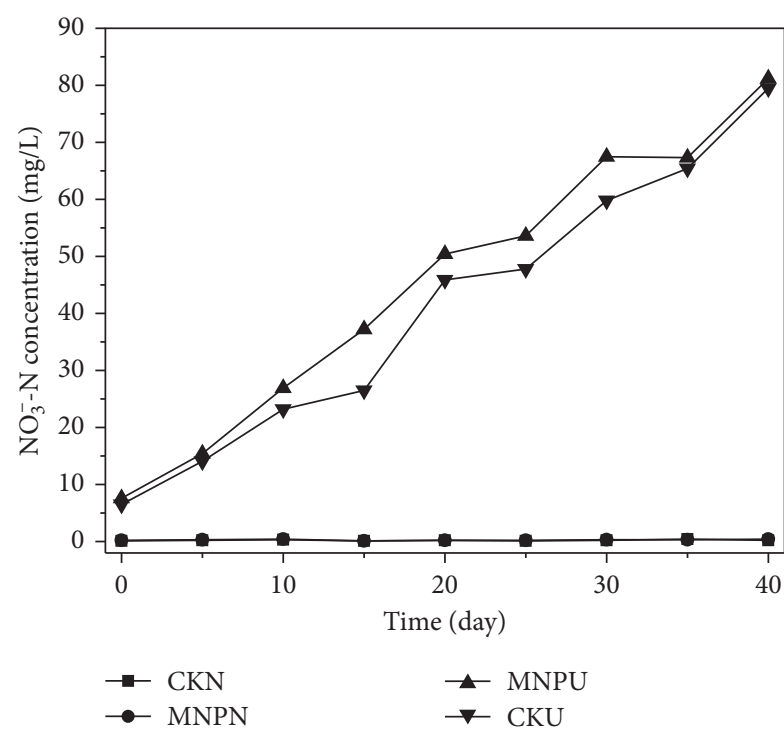

(a)

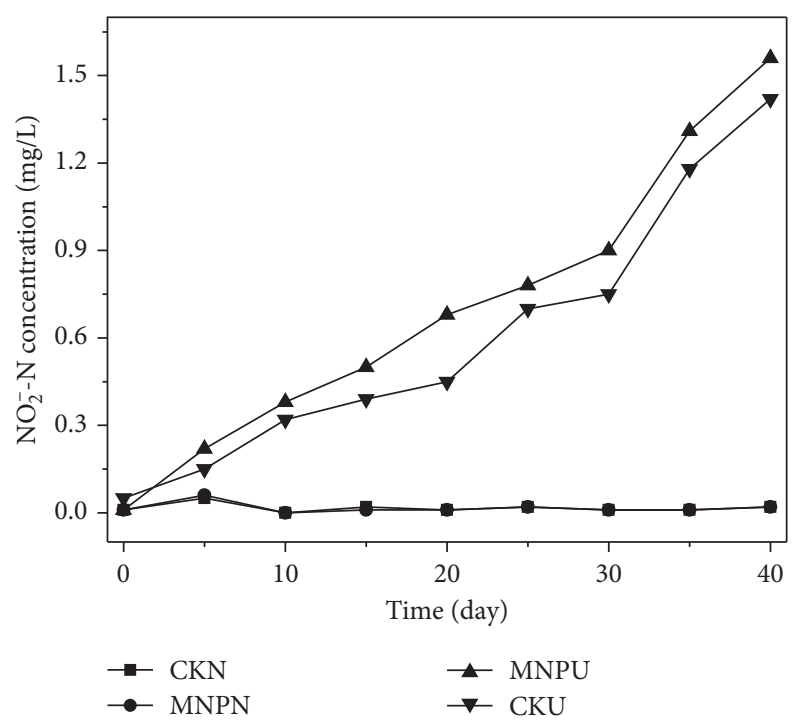

(b)

FIGURE 6: The nitrate (a) and nitrous nitrogen (b) concentration changes, respectively.

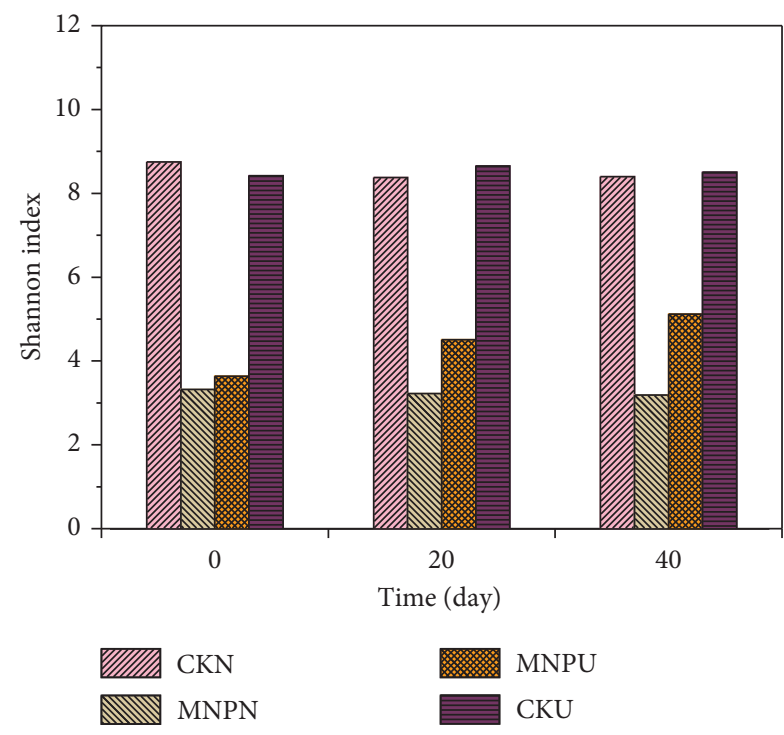

FIgURE 7: Microbial diversity index (Shannon).

Sequence comparison in the constructed libraries revealed that the dominant bacterial phyla include Proteobacteria, Chloroflexi, Bacteroidetes, Spirochaetae, Firmicutes, and Gemmatimonadetes. Proteobacteria (44.3\%$65.1 \%$ ) was the absolute dominant population in all samples [35]. Proteobacteria species are facultative or obligate anaerobes and are Gram-negative bacteria [36]. As reported by Wang et al. [37], in samples of activated sludge collected from a domestic sewage treatment plant after traditional long-term domestication, Proteobacteria finally accounted for $67.3 \%$ of total effective bacterial sequences, which was consistent with the result observed in this study. Proteobacteria include ammonia-oxidizing, nitrite-oxidizing, and denitrifying bacteria, which play an important role in the biological removal of nitrogen [38]. In CKU and MNPU, the number of Proteobacteria gradually increased from $49.9 \%$ (MNPU-0) and 48.9\% (CKU-0) to 65.0\% (MNPU-30) and $63.2 \%$ (CKU-30). On the one hand, the increasing degradation rate of ammonia nitrogen indicates that ammoniaand nitrite-oxidizing Proteobacteria can use urea as a carbon source. On the other hand, it also shows that the addition of MNPs has a certain enrichment effect on functional microorganisms. During days $30-40$ of the reaction, the number of Proteobacteria decreased to $61.1 \%$ (MNPU-40) and $60.8 \%$ (CKU-40); this decrease likely resulted from the decreased nutrient availability in the system at the late stages of the experiment. The decrease mentioned above may facilitate the increase of autotrophic bacteria, such as Firmicutes and Bacteroidetes; these phyla occupy some of the ecological niches of Proteobacteria [39]. In CKN and MNPN, the number of Proteobacteria gradually decreased. This result could also be attributed to dwindling carbon and nutrient concentrations in the system, and heterotrophic microorganisms are also less likely to survive as the carbon nutrient source decreases, thus changing microbial diversity.

Chloroflexi accounted for $6.0 \%-14.3 \%$ of the bacterial phyla in the system. Chloroflexi comprise Gram-negative and facultative or obligate anaerobic bacteria, with important roles in the degradation of organic matter (such as $\mathrm{COD}_{\mathrm{Cr}}$ ) [40]. In the four experimental groups, the number of Chloroflexi decreased during the later stages of the experiment. This decrease may be related to the gradual depletion of organic matter.

Bacteroidetes $(8.3 \%-11.2 \%)$ are the third most dominant bacterial phylum in the reaction system. Bacteroidetes include Gram-negative, organic-nutritive bacteria, and some nitrogen-resistant bacteria (such as Sphingobacteria) that are implicated in denitrification. Certain Bacteroidetes species can also hydrolyze complex solid organic matter, such as proteins and lipids [41]. Hence, in CKU and MNPU, the number of Bacteroidetes gradually increased as the 


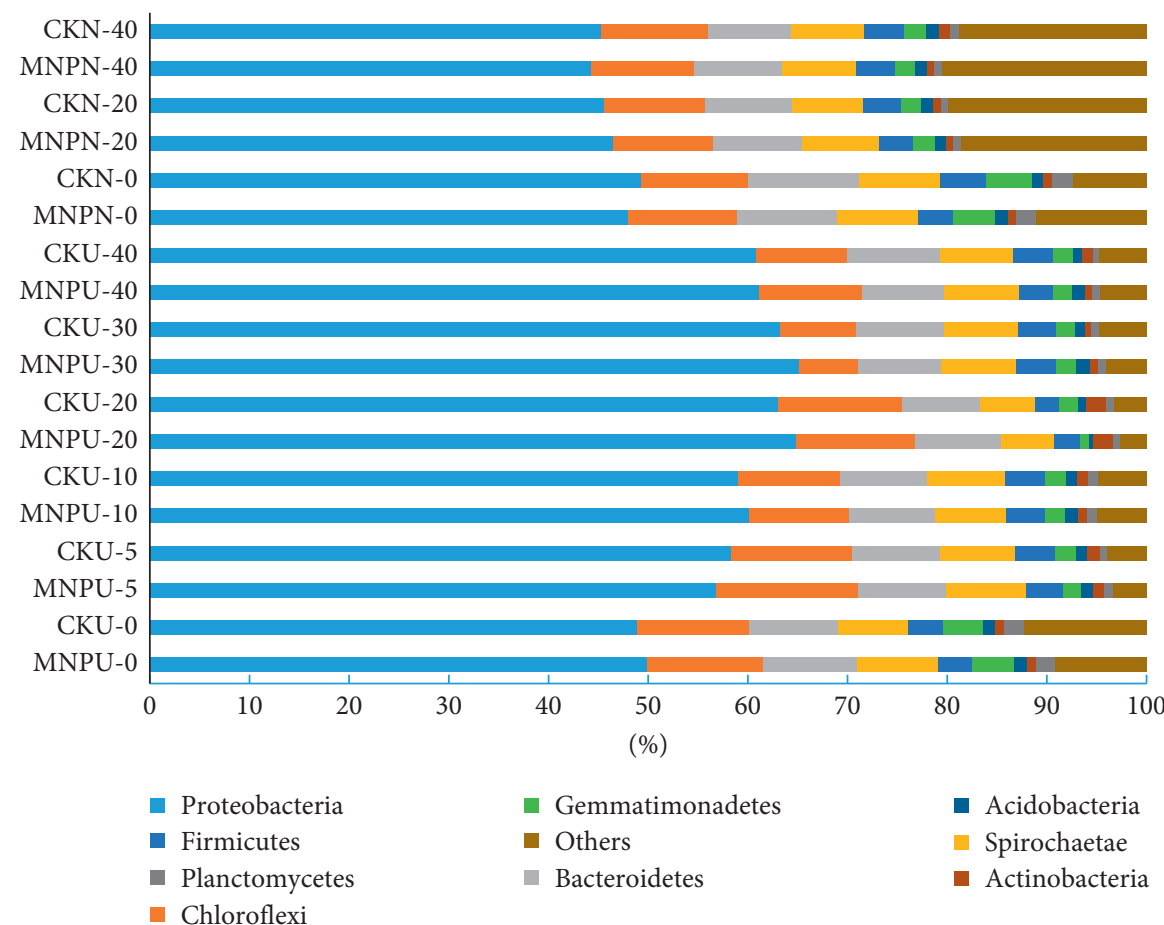

Figure 8: Classification of microbes according to phylum.

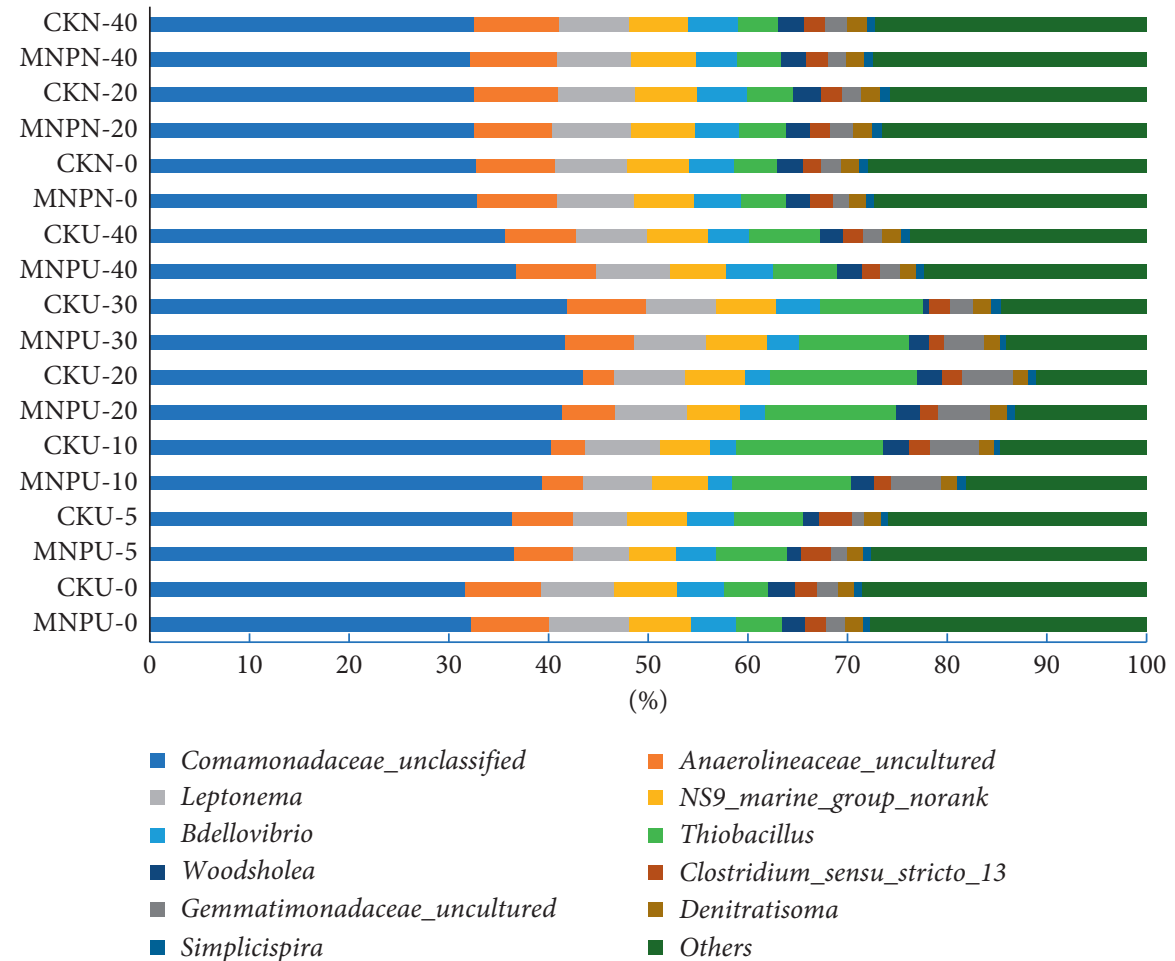

Figure 9: Classification of microbes according to family and genus.

experiment progressed. The increase in the number of Bacteroidetes is related to its two functions mentioned above. However, in $\mathrm{CKN}$ and $\mathrm{MNPN}$, the number of Bacteroidetes decreased significantly. This decrease is likely related to the decrease in organic matter concentration.
3.4.3. Community Composition Analysis at the Family and Genus Levels. In order to understand the effect of MNPs on the community structure during ammonia nitrogen degradation, the bacterial community composition was also analyzed at the taxonomic level of the family and genus (Figure 9). 


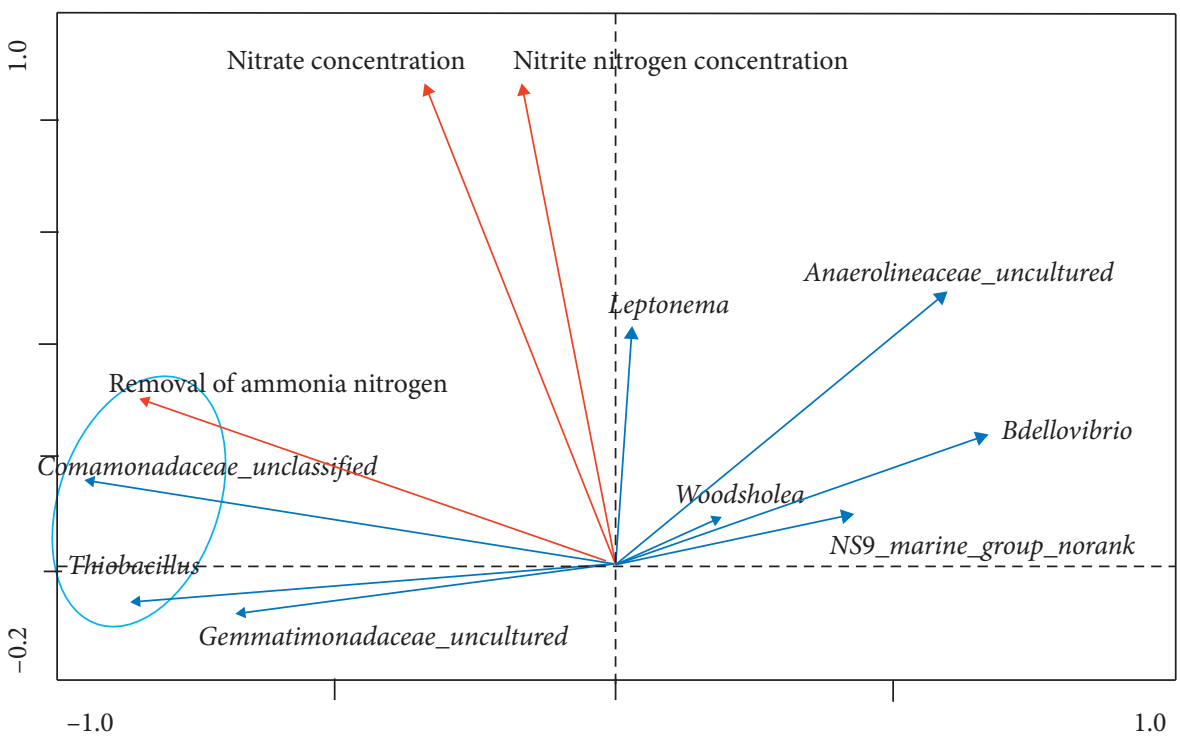

FIGURE 10: RDA analysis of advantage bacterium and major environmental factor.

The dominant genera included Comamonadaceae_unclassified (32.2\%-43.5\%), Thiobacillus (4.4\%-15.0\%), Anaerolineaceae_uncultured (3.1\%-8.6\%), Leptonema (5.5\%-8.1\%), NS9_marine_group_ norank (5.2\%-6.6\%), Bdellovibrio (2.3\%-4.9\%), Gemmatimonadaceae_uncultured (1.2\%-5.2\%), and Woodsholea $(0.7 \%-2.8 \%)$.

In MNPU and CKU, the population of Comamonadaceae_unclassified, Thiobacillus, Leptonema, and Gemmatimonadaceae_uncultured and the degradation rate for ammonia nitrogen gradually increased from the start of the reaction to approximately 30 days of the experiment. After 30 days, the bacterial population and degradation rate both decreased.

Among them, the changes in the numbers of $\beta$-Proteobacteria Comamonadaceae_unclassified and Thiobacillus were the most obvious. In addition, Park et al. [42] observed that in the process of processing high-intensity nitrogen wastewater through a hollow fiber-membrane biofilm reactor system, the Comamonadaceae and Thiobacillus were also the dominant bacteria. Comamonadaceae_unclassified, which has excellent ammonia-degrading ability, is present in nitrification-denitrification activated sludge [43]. Thiobacillus is mainly present in sediments and moist soils. Thiobacillus denitrificans in genus Thiobacillus is a sulfur autotrophic and denitrifying bacterium [2]. T. denitrificans is a common bacterium in sewage treatment. T. denitrificans utilizes nitrates as electron acceptors to produce nitrogen under limited carbon conditions. This microbe also oxidizes sulfur-containing compounds to form sulfates [44, 45]. Figure 9 shows that the population of Thiobacillus significantly increased at all stages (MNPU: $7.3 \%$ to $15.0 \%$; CKU: $7.2 \%$ to $12.2 \%$ ). This increase is related to the strong nitratereducing capacity of Thiobacillus. Therefore, Comamonadaceae_unclassified and Thiobacillus should dominate the degradation of ammonia nitrogen. In the experimental group with MNPs, the active nitrogen degraders gradually lost their magnetic properties due to splitting, and remained in the MFCU component. Therefore, the populations of these two bacteria were higher in MNPU than CKU, which further confirms that the MNPs had a good aggregation effect on the functionalized degradation bacteria.

The population of Leptonema and Gemmatimonadaceae_uncultured increased with the degradation rate of ammonia nitrogen. This change, however, was not very obvious. Leptonema belongs to Leptospirosis. Gemmatimonadaceae_uncultured is a class of Gram-negative bacteria. Zhang et al. [46] successfully isolated Gemmatimonas aurantiaca, which belongs to Gemmatimonadaceae, and found that it has a high capacity for phosphorus degradation. At present, studies on these two bacteria are limited.

In addition, Anaerolineaceae_uncultured, which belongs to Chloroflexi, was present in the reaction system. This microbe, which can degrade carbohydrates, amino acids, and other cell materials, is usually present in the soil. Studies have also shown that this microbe can decrease the concentration of sulfide and ammonia in the soil [47]. Guo et al. [48] found that Anaerolineaceae_uncultured and NS9_marine_group_norank were relatively rich in a sequencing batch reactor (PNSFD-SBR), and both Anaerolineaceae_uncultured and NS9_marine_group_norank dominated the sludge fermentation and denitrification process. Moreover, the population of these two bacterial species initially decreased and then increased. This pattern likely occurred because the bacteria gradually adapted to the new environment in the process, thus improving nitrogen removal.

Bdellovibrio is a class of parasites that can infect and attack microorganisms and cause microbial cleavage. Bdellovibrio has a strong ability to lyse protein and can use the amino acids of host cells to grow and reproduce [49]. These bacteria are ubiquitous in nature and can be detected in sewage, sediments, and contaminated rivers at various stages of treatment. 
From Figures 8 and 9, the increase and decrease of dominant bacteria in CKN were consistent with MNPN, indicating that the MNPs do not adversely affect ammonia nitrogen degradation. In the meantime, the external carbon source promoted the succession of the sludge community structure via long-term domestication, and the addition of MNPs improved the community structure to a certain extent and made it more adaptive to changes in the external environment.

3.4.4. RDA Analysis of Dominant Bacterium. Figure 10 shows the RDA of the dominant bacterium and major environmental factors. It provided further evidence that Comamonadaceae_unclassified and Thiobacillus were highly correlated with the ammonia nitrogen removal rate. It has been proved again that MNPs have a good aggregation effect on functional degrading bacteria. This method provides opportunities for deeper insights into the actual roles and ecological traits of the activated sludge and helps in effective management for WWTPs.

\section{Conclusions}

In the present study, the functional nitrogen degraders were identified from the active sludge after long-term treatment. We found that the degradation efficiency of ammonia nitrogen gradually increased with the progress of the reaction in the two experimental groups with an added carbon source. Ten days after the start of the reaction, the degradation rate of ammonia nitrogen exceeded $80 \%$ and with a maximum value of $91.6 \%$. The degradation rates in MNPU were higher than those in other samples, which indicated that MNPs enriched the numbers of ammonia nitrogendegrading bacteria and increased the degradation rate of ammonia nitrogen.

High-throughput sequencing revealed that the Shannon indexes of CKU, CKN, and MNPN were stable over the whole experimental period. However, the Shannon index of MNPU increased continuously during the reaction, indicating that functional nitrogen degraders gradually dominated the reaction system and that the MNPs successfully separated ammonia nitrogen-degrading bacteria from the system.

Analysis of the microbial community structure revealed that at the phylum level, Proteobacteria, Chloroflexi, and Bacteroidetes dominated the microbial community. At the family and genus levels, Comamonadaceae_unclassified, Thiobacillus, and Anaerolineaceae_uncultured dominated. RDA showed that Comamonadaceae_unclassified and Thiobacillus were identified as the functional nitrogen degraders in the system. The differences in the community structure of the nitrogen degraders between groups with or without MNPs suggested that MMI is an efficient method for identifying functional yet uncultivable degraders for contaminant in situ. Our work also proves that the addition of MNPs can improve the long-term acclimated sludge and make it more adaptable to the newly introduced pollutants.

\section{Data Availability}

All data analyzed or generated during the study are included within the article.

\section{Conflicts of Interest}

The authors declare that they have no conflicts of interest.

\section{Acknowledgments}

This research was supported by the National Natural Science Foundation of China (Grant no. 51378064) and "Double First-class” Project Fund of Beijing Normal University.

\section{References}

[1] Ministry of Environmental Protection of the People's Republic of China, China State of the Environment Bulletin, Ministry of Environmental Protection, Beijing, China, 2015.

[2] M. Chen, X.-F. Zhou, Y.-Q. Yu et al., "Light-driven nitrous oxide production via autotrophic denitrification by selfphotosensitized Thiobacillus denitrificans," Environment International, vol. 127, pp. 353-360, 2019.

[3] F. Zhang, Y. Peng, Z. Wang, and H. Jiang, "High-efficient nitrogen removal from mature landfill leachate and waste activated sludge (WAS) reduction via partial nitrification and integrated fermentation-denitritation process (PNIFD)," Water Research, vol. 160, pp. 394-404, 2019.

[4] Z. Wang, X. Zhang, X. Lu et al., "Abundance and diversity of bacterial nitrifiers and denitrifiers and their functional genes in tannery wastewater treatment plants revealed by highthroughput sequencing," PLoS One, vol. 9, no. 11, Article ID e113603, 2014.

[5] T. Zhang, L. Ye, A. H. Y. Tong, M.-F. Shao, and S. Lok, "Ammonia-oxidizing archaea and ammonia-oxidizing bacteria in six full-scale wastewater treatment bioreactors," $A p$ plied Microbiology and Biotechnology, vol. 91, no. 4, pp. 1215-1225, 2011.

[6] I. M. Head, W. D. Hiorns, T. M. Embley, A. J. Mccarthy, and J. R. Saunders, "The phylogeny of autotrophic ammoniaoxidizing bacteria as determined by analysis of $16 \mathrm{~S}$ ribosomal RNA gene sequences," Journal of General Microbiology, vol. 139, no. 6, pp. 1147-1153, 1993.

[7] A. Teske, E. Alm, J. M. Regan, S. Toze, B. E. Rittmann, and D. A. Stahl, "Evolutionary relationships among ammonia-and nitrite-oxidizing bacteria," Journal of Bacteriology, vol. 176, no. 21, pp. 6623-6630, 1994.

[8] I. Kasuga, H. Nakagaki, F. Kurisu, and H. Furumai, "Predominance of ammonia-oxidizing archaea on granular activated carbon used in a full-scale advanced drinking water treatment plant," Water Research, vol. 44, no. 17, pp. 50395049, 2010.

[9] S. Leininger, T. Urich, M. Schloter et al., "Archaea predominate among ammonia-oxidizing prokaryotes in soils," Nature, vol. 442, no. 7104, pp. 806-809, 2006.

[10] G. W. Nicol and C. Schleper, "Ammonia-oxidising Crenarchaeota: important players in the nitrogen cycle?" Trends in Microbiology, vol. 14, no. 5, pp. 207-212, 2006.

[11] M. Könneke, A. E. Bernhard, J. R. de la Torre, C. B. Walker, J. B. Waterbury, and D. A. Stahl, "Isolation of an autotrophic ammonia-oxidizing marine archaeon," Nature, vol. 437, no. 7058, pp. 543-546, 2005. 
[12] J. R. de la Torre, C. B. Walker, A. E. Ingalls, M. Könneke, and D. A. Stahl, "Cultivation of a tmophilic ammonia oxidizing archaeon synthesizing crenarchaeol," Environmental Microbiology, vol. 10, no. 3, pp. 810-818, 2008.

[13] S.-J. Park, G. Rohit, M.-C. Ana-Belen et al., "Genomes of two new ammonia-oxidizing archaea enriched from deep marine sediments," PLoS One, vol. 9, no. 5, Article ID e96449, 2014.

[14] P. C. Blainey, A. C. Potanina, C. A. Francis, and S. R. Quake, "Genome of a low-salinity ammonia-oxidizing archaeon determined by single-cell and metagenomic analysis," PLos One, vol. 6, no. 2, Article ID e16626, 2011.

[15] L. E. Lehtovirta-Morley, K. Stoecker, A. Vilcinskas, J. I. Prosser, and G. W. Nicol, "Cultivation of an obligate acidophilic ammonia oxidizer from a nitrifying acid soil," Proceedings of the National Academy of Sciences, vol. 108, no. 38, pp. 15892-15897, 2011.

[16] A. C. Mosier, E. E. Allen, M. Kim, S. Ferriera, and C. A. Francis, "Genome sequence of "Candidatus Nitrosoarchaeum limnia" BG20, a low-salinity ammonia-oxidizing archaeon from the san francisco bay estuary," Journal of Bacteriology, vol. 194, no. 8, pp. 2119-2120, 2012.

[17] Z. Huang, P. B. Gedalanga, P. Asvapathanagul, and B. H. Olson, "Influence of physicochemical and operational parameters on Nitrobacter and Nitrospira communities in an aerobic activated sludge bioreactor," Water Research, vol. 44, no. 15 , pp. 4351-4358, 2010.

[18] D.-J. Kim and S.-H. Kim, "Effect of nitrite concentration on the distribution and competition of nitrite-oxidizing bacteria in nitratation reactor systems and their kinetic characteristics," Water Research, vol. 40, no. 5, pp. 887-894, 2006.

[19] H.-P. Koops and A. Pommerening-Röser, "Distribution and ecophysiology of the nitrifying bacteria emphasizing cultured species," Fems Microbiology Ecology, vol. 37, no. 1, pp. 1-9, 2001.

[20] R. Nogueira and L. F. Melo, "Competition between Nitrospira spp. and Nitrobacter spp. in nitrite-oxidizing bioreactors," Biotechnology and Bioengineering, vol. 95, no. 1, pp. 169-175, 2006.

[21] S. Siriping and B. E. Rittmann, "Diversity study of nitrifying bacteria in full-scale municipal wastewater treatment plants," Water Research, vol. 41, no. 5, pp. 1100-1120, 2007.

[22] T. Kaeberlein, K. Lewis, and S. S. Epstein, "Isolating "uncultivable" microorganisms in pure culture in a simulated natural environment," Science, vol. 296, no. 5570, pp. 11271129, 2002.

[23] R. F. Fakhrullin and V. N. Paunov, "Fabrication of living cellosomes of rod-like and rhombohedral morphologies based on magnetically responsive templates," Chemical Communications, vol. 18, no. 18, pp. 2511-2513, 2009.

[24] A. K. F. Dyab, M. Ozmen, M. Ersoz, and V. N. Paunov, "Fabrication of novel anisotropic magnetic microparticles," Journal of Materials Chemistry, vol. 19, no. 21, pp. 3475-3481, 2009.

[25] X. Zhao, H. Li, A. Ding, G. Zhou, Y. Sun, and D. Zhang, "Preparing and characterizing $\mathrm{Fe}_{3} \mathrm{O}_{4} @$ cellulose nanocomposites for effective isolation of cellulose-decomposing microorganisms," Materials Letters, vol. 163, pp. 154-157, 2015.

[26] D. Zhang, J. P. Berry, D. Zhu et al., "Magnetic nanoparticlemediated isolation of functional bacteria in a complex microbial community," The ISME Journal, vol. 9, no. 3, pp. 603-614, 2015.

[27] X. Wang, X. Zhao, H. Li et al., "Separating and characterizing functional alkane degraders from crude- oil-contaminated sites via magnetic nanoparticle-mediated isolation," Research in Microbiology, vol. 167, no. 9-10, pp. 731-744, 2016.

[28] D. Y. Zhang, R. F. Fakhrullin, M. Özmen et al., "Functionalization of whole-cell bacterial reporters with magnetic nanoparticles," Microbial Biotechnology, vol. 4, no. 1, pp. 89-97, 2014.

[29] T. Coenye and P. Vandamme, "Intragenomic heterogeneity between multiple 16S ribosomal RNA operons in sequenced bacterial genomes," FEMS Microbiology Letters, vol. 228, no. 1, pp. 45-49, 2003.

[30] American Public Health Association, APHA Standard Methods for the Examination of Water and Wastewater, American Public Health Association, Washington, DC, USA, 1998.

[31] S. Kazemifard, H. Nayebzadeh, N. Saghatoleslami, and E. Safakish, "Assessment the activity of magnetic $\mathrm{KOH} /$ $\mathrm{Fe}_{3} \mathrm{O}_{4} @ \mathrm{Al}_{2} \mathrm{O}_{3}$ core-shell nanocatalyst in transesterification reaction: effect of $\mathrm{Fe} / \mathrm{Al}$ ratio on structural and performance," Environmental Science and Pollution Research, vol. 25, no. 32, pp. 32811-32821, 2018.

[32] R. S. Bangari, A. K. Singh, S. Namsani, J. K. Singh, and N. Sinha, "Magnetite-coated boron nitride nanosheets for the removal of arsenic(V) from water," ACS Applied Materials \& Interfaces, vol. 11, no. 21, pp. 19017-19028, 2019.

[33] X. Y. Cui, J. Yin, Y. Lin, N. Li, M. Wang, and D. S. Shen, "Towards a definition of harmless nanoparticles from an environmental and safety perspective," Journal of Chemistry, vol. 2016, Article ID 8608567, 12 pages, 2016.

[34] Z. Lin, Y. Xu, Z. Zhen et al., "Application and reactivation of magnetic nanoparticles in Microcystis aeruginosa harvesting," Bioresource Technology, vol. 190, pp. 82-88, 2015.

[35] Z. Wang, Y. Yang, Y. Dai, and S. Xie, "Anaerobic biodegradation of nonylphenol in river sediment under nitrate-or sulfate-reducing conditions and associated bacterial community," Journal of Hazardous Materials, vol. 286, pp. 304314, 2015.

[36] Y. Yang, Y. Dai, Z. Wu, S. Xie, and Y. Liu, “Temporal and spatial dynamics of archaeal communities in two freshwater lakes at different trophic status," Frontiers in Microbiology, vol. 7, 2016.

[37] B. Wang, M. Zhao, Y. Guo, Y. Peng, and Y. Yuan, "Long-Term partial nitritation and microbial characteristics in treating low $\mathrm{C} / \mathrm{N}$ ratio domestic wastewater," Environmental Science: Water Research \& Technology, vol. 4, no. 6, pp. 820-827, 2018.

[38] M. Kumar and J.-G. Lin, "Co-existence of anammox and denitrification for simultaneous nitrogen and carbon removal-Strategies and issues," Journal of Hazardous Materials, vol. 178, no. 1-3, pp. 1-9, 2010.

[39] H. Lu, Z. Xue, P. Saikaly, S. P. Nunes, T. R. Bluver, and W.-T. Liu, "Membrane biofouling in a wastewater nitrification reactor: microbial succession from autotrophic colonization to heterotrophic domination," Water Research, vol. 88, pp. $337-345,2016$.

[40] L. M. C. Daniel, E. Pozzi, E. Foresti, and F. A. Chinalia, "Removal of ammonium via simultaneous nitrification-denitrification nitrite-shortcut in a single packed-bed batch reactor," Bioresource Technology, vol. 100, no. 3, pp. 1100-1107, 2009.

[41] V. R. Hill, A. M. Kahler, N. Jothikumar, T. B. Johnson, D. Hahn, and T. L. Cromeans, "Multistate evaluation of an ultrafiltration-based procedure for simultaneous recovery of enteric microbes in 100-liter tap water samples," Applied and Environmental Microbiology, vol. 73, no. 13, pp. 4218-4225, 2007. 
[42] J.-H. Park, O. Choi, T.-H. Lee, H. Kim, and B.-I. Sang, "Pyrosequencing analysis of microbial communities in hollow fiber-membrane biofilm reactors system for treating highstrength nitrogen wastewater," Chemosphere, vol. 163, pp. 192-201, 2016.

[43] A.-J. Li, S.-F. Yang, X.-Y. Li, and J.-D. Gu, "Microbial population dynamics during aerobic sludge granulation at different organic loading rates," Water Research, vol. 42, no. 13, pp. 3552-3560, 2008.

[44] W. Tao, J. Wen, Y. Han, and M. P. Huchzermeier, "Nitrogen removal in constructed wetlands using nitritation/anammox and nitrification/denitrification: effects of influent nitrogen concentration," Water Environment Research, vol. 84, no. 84, pp. 2099-2105, 2012.

[45] M. G. Prokopenko, M. B. Hirst, L. De Brabandere et al., "Nitrogen losses in anoxic marine sediments driven by Thioploca-anammox bacterial consortia," Nature, vol. 500, no. 7461, pp. 194-198, 2013.

[46] H. Zhang, Y. J. Sekiguchi, S. Hanada et al., "Gemmatimonas aurantiaca gen. nov., sp. nov., a Gram-negative, aerobic, polyphosphate-accumulating micro-organism, the first cultured representative of the new bacterial phylum Gemmatimonadetes phyl. nov," International Journal of Systematic and Evolutionary Microbiology, vol. 53, no. 4, pp. 1155-1163, 2003.

[47] T. Yamada, Y. Sekiguchi, H. Imachi, Y. Kamagata, A. Ohashi, and H. Harada, "Diversity, localization, and physiological properties of filamentous microbes belonging to Chloroflexi subphylum I in mesophilic and thermophilic methanogenic sludge granules," Applied and Environmental Microbiology, vol. 71, no. 11, pp. 7493-7503, 2005.

[48] Y. Guo, Y. Peng, B. Wang, B. Li, and M. Zhao, "Achieving simultaneous nitrogen removal of low $\mathrm{C} / \mathrm{N}$ wastewater and external sludge reutilization in a sequencing batch reactor," Chemical Engineering Journal, vol. 306, no. 15, pp. 925-932, 2016.

[49] S. Feng, C. H. Tan, F. Constancias et al., "Predation by Bdellovibrio bacteriovorus significantly reduces viability and alters the microbial community composition of activated sludge flocs and granules," FEMS Microbiology Ecology, vol. 93, no. 4, Article ID fix020, 2017. 